\title{
Preparation and Characterization of Nano-Polyaniline Film on ITO Conductive Glass by Electrochemical Polymerization
}

\author{
Qi Qin", and Yunxia Guo ${ }^{3}$ \\ ${ }^{1}$ School of Materials and Chemical Engineering, Zhongyuan University of Technology, 41 Zhongyuan Road, \\ Zhengzhou 450007, China \\ ${ }^{2}$ School of Materials Science and Engineering, Zhengzhou University, 100 Kexue Road, Zhengzhou 450001, China \\ ${ }^{3}$ College of Material Science and Technology, Nanjing University of Aeronautics and Astronautics, 29 Yudao Street, \\ Nanjing 210016, China
}

Correspondence should be addressed to Qi Qin, qq821223@126.com

Received 16 October 2011; Accepted 10 December 2011

Academic Editor: Arava Leela Mohana Reddy

Copyright (C) 2012 Q. Qin and Y. Guo. This is an open access article distributed under the Creative Commons Attribution License, which permits unrestricted use, distribution, and reproduction in any medium, provided the original work is properly cited.

Polyaniline (PANI) films were synthesized on a conducting ITO glass by potentiostatic techniques to construct a low-cost counter electrode for dye-sensitized solar cell (DSSC). The compact layer, nanoparticles, nanorods- and fibrils were observed on the top of PANI films with different constant potentials by SEM. Then the conductivity test illuminated that a polyaniline film with the highest conductivity was electrodeposited at $1.0 \mathrm{~V}$. Finally, the photoelectric measurement showed that the energy conversion efficiency of DSSC with the PANI electrode was increased with the potential decreasing. And the efficiency of DSSC with PANI counter electrode at $1.0 \mathrm{~V}$ was higher than that with Pt electrode, owing to the high surface area, high conductivity, and excellent catalytic activity of PANI electrode. Therefore, the PANI counter electrode with excellent catalytic performance is a potential substitute for platinized electrode to save cost of DSSC.

\section{Introduction}

Dye-sensitized solar cells have been one of the most promising photovoltaic devices due to their high conversion efficiency and low cost. In general, a DSSC comprises a dye-sensitized titanium dioxide $\left(\mathrm{TiO}_{2}\right)$ electrode, an iodide/ triiodide redox electrolyte solution, and a counter electrode (CE). The function of the CE is to transfer electrons from the external circuit back to the redox electrolyte and to catalyze the reduction of the triiodide ion [1-4]. Usually, a Pt electrode formed on a transparent conductive glass substrate is used as the CE for DSSC. Although Pt exhibits excellent catalytic activity for triiodide reduction and good electric conductivity, it is extremely expensive and has the problem of reserves for large-scale application [5, 6]. Meanwhile, the shape limitation will bring transport problem for the $\mathrm{Pt}$ counter electrode. Future large solar electric conversion systems will prefer materials abundantly available and easily handled. Therefore, it is necessary to develop cheap materials for CEs which also exhibit high electrical conductivity, good chemical stability, and good catalytic activity to the reduction of triiodide ion.

So far, inexpensive carbonaceous materials and conducting polymers such as graphite, carbon black, carbon nanotube, graphene, poly(3,4-propylenedioxythiophene) (PProDOT), and poly(3,4-ethylenedioxythiophene) (PEDOT) have been employed as the catalytic materials on indium tin oxide (ITO) glass for the CEs. Yen et al. reported a DSSC using the carbon nanotube composite plate had a cell efficiency of $4.73 \%$ [7]. Meanwhile, Saito et al. used chemically polymerized PEDOT on fluorine-doped tin oxide (FTO) glass as the counter electrodes and obtained a conversion efficiency of $3.6 \%$ under $100 \mathrm{mWcm}^{-2}$ [8]. Fukuri and coworkers also developed PEDOT-based solidstate electrolytes, but the cell efficiencies were $<1 \%$ [9].

Recently, the conducting PANI was applied as the counter electrode materials for DSSC to replace the platinized counter electrode due to its easy synthesis, high conductivity, and unique redox properties [10]. Among the previous research, the electrode with a layer of conductive PANI coated on 
conducting glass is achieved by using several methods, such as the spreading of a solution of conductive polymer on the surface of the material followed by the evaporation of the solvent [11], the in situ chemical polymerization, and then deposition on the surfaces of various materials immersed in the polymerization solution [12] or the electropolymerization of the monomers on an electrode [13-16]. Wu et al. researched on using polyaniline [5] or polypyrrole [6] as counter electrode in DSSCs by the vertical dip-tugging method [17, 18]. Moreover, it was reported that PANI was deposited on the surface of ITO conductive glass by in situ chemical polymerization [19], and the energy conversion efficiency of DSSC with PANI counter electrode reached $2.64 \%$. However, these methods were difficult to obtain a homogeneous and compact film owing to the insolubility or poor solubility of PANI in nearly all solvents [20].

Hence, the method of electropolymerization to prepare a compact film of polyaniline is considered in this study. The PANI counter electrodes are prepared on the surface of conducting glass by using potentiostatic techniques, and the photoelectric performances of DSSC with these electrodes are also discussed.

\section{Experimental}

2.1. Materials. Aniline (An, analytical grade from Sinopharm Chemical Reagent Co., Ltd) was purified by distillation under reduced pressure prior to usage. Analytical-grade reagents, $\mathrm{H}_{2} \mathrm{SO}_{4}$, iodine, lithium perchlorate, acetonitrile, ethanol, and acetone (Sinopharm Chemical Reagent Co., Ltd), were used without any pretreatment. All solutions were prepared from deionized water. ITO glasses from the Institute of Plasma Physics (CAS) were used as the substrates. Anhydrous lithium iodide, 4-tert-butylpyridine, 1methyl-3-propylimidazolium iodide, methoxypropionitrile were provided by Fluka Chemical Corporation. $\mathrm{TiO}_{2}$ colloid and dye N719 were the commercial product purchased from Solaronix SA (Switzerland). Pt counter electrode bought from Dyesol Limited was used in the contrast test.

2.2. Preparation of PANI Electrode. ITO glasses were rinsed with deionized water and immersed in ethanol ultrasonically for $15 \mathrm{~min}$, then immersed in acetone ultrasonically for 15 min before PANI electropolymerization. One ITO glass sheet was used as working electrode for PANI deposition. The deposited area was $1 \mathrm{~cm}^{2}$ with other area insulated by an adhesive tape coating. A Pt sheet was used as the counter electrode. PANI was electrodeposited on the surface of ITO glass by potentiostatic method at different constant potential $(1.0 \mathrm{~V}, 1.1 \mathrm{~V}, 1.2 \mathrm{~V}$, and $1.3 \mathrm{~V}$ ) for $500 \mathrm{~s}$ in a $0.2 \mathrm{M}$ aniline/0.5 $\mathrm{M}$ sulphuric acid $\left(\mathrm{H}_{2} \mathrm{SO}_{4}\right)$ electrolyte solution. Finally, PANI-modified glass electrode was immersed in $0.5 \mathrm{M} \mathrm{H}_{2} \mathrm{SO}_{4}$ statically in order to expel aniline monomer and oligomer PANI from the polymeric film and then rinsed with deionized water and ethanol for several times and dried in a vacuum at $60^{\circ} \mathrm{C}$ for $24 \mathrm{~h}$.

2.3. Assembling of DSSCs. Nano- $\mathrm{TiO}_{2}$ colloid was dropped on the ITO glass plate by a doctor scraping technique to form a porous film. Then the $\mathrm{TiO}_{2}$ porous film was sintered by annealing at $450^{\circ} \mathrm{C}$ for $30 \mathrm{~min}$. After cooling to $100^{\circ} \mathrm{C}$, the $\mathrm{TiO}_{2}$ film was immersed in an ethanol solution of N719 dye for $24 \mathrm{~h}$. Finally, DSSC was assembled by injecting a drop of electrolyte with I2, LiI, 1-methyl-3-propylimidazolium iodide, 4-tert-butylpyridine in methoxypropionitrile into the aperture between the $\mathrm{TiO}_{2}$ porous film electrode and the PANI electrode.

2.4. Measurement and Characterization. The SEM image of the sample was performed using a scanning electron microscopy (LEO1550, GER). FTIR spectrum of the PANI was recorded in the range of $500-4000 \mathrm{~cm}^{-1}$ using FTIR spectroscopy (Perkin Elmer 1760, USA). The conductivity of PANI was measured by manual four probe instrument (MP 1008, WENTWORTH, UK). Photocurrent-voltage characteristics of the DSSCs were obtained by a Keithley model 2400 digital source meter using an Oriel 91192 solar simulator equipped with AM 1.5 filter and intensity of $100 \mathrm{~mW} / \mathrm{cm}^{2}$. All the polymerization experiments were performed on an electrochemical workstation (CHI660A, CHInstrument, $\mathrm{CHN}$ ).

\section{Results and Discussion}

3.1. Micromorphology of PANI. The photograph of the polyaniline films electrodeposited at $1.0,1.1,1.2$, and $1.3 \mathrm{~V}$ on the ITO substrate is shown in Figure 1. It can be seen the emerald PANI thin layer is deposited on glass from Figure 1(a). With the electropolymerization potential rising, the thickness of PANI layer has a significant increase, and the color of PANI film becomes darker and darker. The PANI film electrodeposited at $1.3 \mathrm{~V}$ closes to dark green.

Figure 2 shows the SEM images of PANI electrodes at different constant potentials. At the low potential $(1.0 \mathrm{~V})$, PANI nuclei grow on the bare electrode to form a compact layer, which adhered to the electrode surface strongly. Increasing the potential to $1.1 \mathrm{~V}$, some PANI particles with the diameter in range of $800 \mathrm{~nm}$ appear on the top of PANI nodules layer. As the potential shifts to more positive potential, the PANI particles disappear and the nanorods emerge on the surface of PANI film. At $1.2 \mathrm{~V}$, PANI mainly forms the short nanorods with the length of $500 \mathrm{~nm}$ and with the diameter of $100 \mathrm{~nm}$. At the higher potential, the PANI deposition shows an extensive fibril growth. At 1.3 V, PANI forms the long fibril with the length of $1 \mu \mathrm{m}$ and with the diameter of $100 \mathrm{~nm}$. This growth of PANI has no directional alignment, and the nanorods or fibrils are nonuniform. It is clearly demonstrated that the formation of thick, short nanorods is preferred at low polymerization potential while the development of thin, long fibrils is more easily achieved at higher potential.

3.2. Molecular Structure of PANI. Figure 3 shows the FTIR spectra of PANI deposited on conductive glass at different potentials. It is clear that the characteristic peaks of polyaniline $\left(\mathrm{KBr}\right.$, thin film, $\left.\mathrm{cm}^{-1}\right)$ present near the wavenumbers of 1561 (C-C stretching mode for the quinoid ring), 1484 (benzenoid rings vibration), 1295 (C-N stretching mode), 


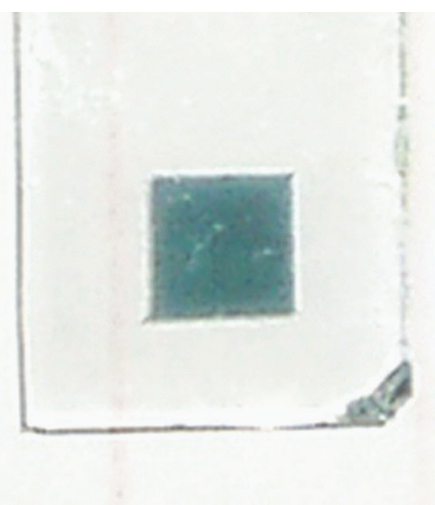

(a)

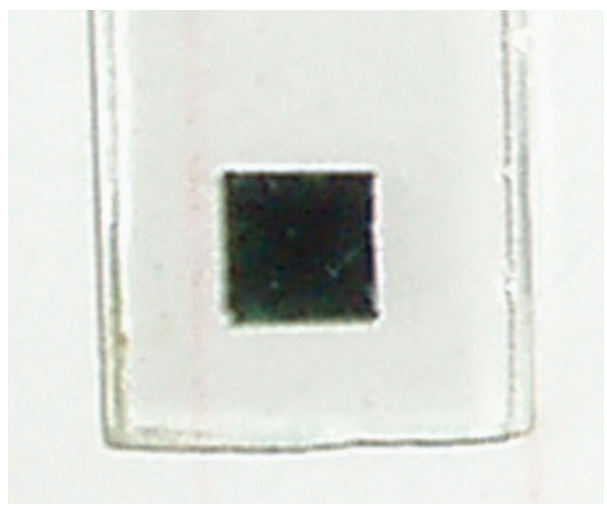

(c)

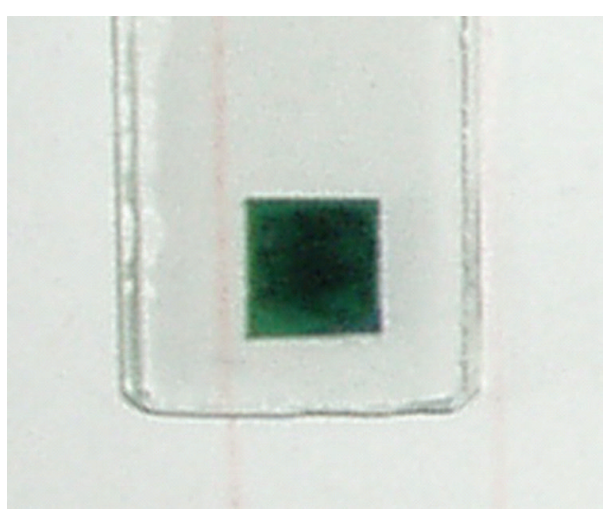

(b)

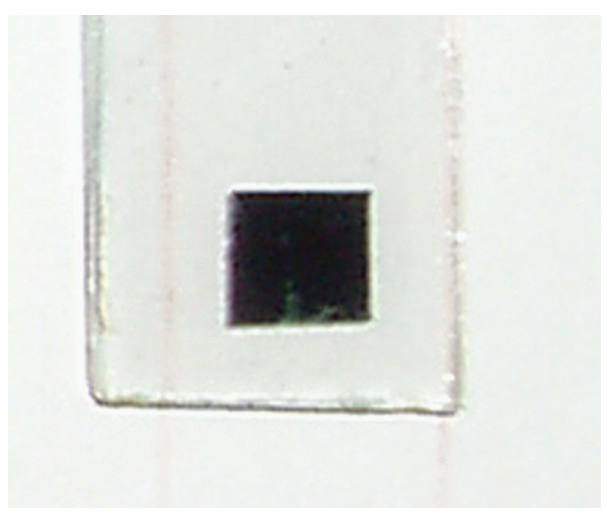

(d)

FIgure 1: The photograph of PANI films electrodeposited at (a) 1.0, (b) 1.1, (c) 1.2, (d) $1.3 \mathrm{~V}$.

$1240\left(\mathrm{C}-\mathrm{N}^{+}\right.$stretching vibration), 1077 (a vibration mode of the $-\mathrm{NH}^{+}=$structure), and 792 (out-of-plane bending vibration of $\mathrm{C}-\mathrm{H}) \mathrm{cm}^{-1}$ [21-27]. As the potential reaches to $1.3 \mathrm{~V}$, the characteristic peaks of PANI become stronger, and the band intensity significantly enhances with the gradual rise of constant potential. It indicates that the PANI can be formed by potentiostatic polymerization at $1.0 \mathrm{~V}$, and the more PANI obtained with the potential increasing can make the peak intensity of PANI stronger.

3.3. Conductivity Measurement. The conductivity of PANI deposited at different potentials is measured by four-point probes instrument and then calculated by this equation:

$$
\sigma=\frac{\ln 2}{\pi d} \cdot \frac{I_{12}}{U_{34}}
$$

where $\sigma$ is the conductivity, $d$ is the thickness of films, $I_{12}$ is the current from 1 to 2 points, and $U_{34}$ is the potential difference between 3 and 4 points. The schematic diagram of four-point probes method is shown in Figure 4.

Meanwhile, polymer thickness is estimated from the amount of charge $Q_{A}$ according to the equation [28]:

$$
d=\frac{Q_{A} M_{w}}{z F A \rho}
$$

where $Q_{A}$ is the charge under the potentiostatic electrodeposition, $M_{w}$ is molecular weight of aniline, $z=0.5$ (number of electrons/aniline unit), $A$ is area of the electrode, $\rho$ is specific density of aniline, and $F$ is Faraday's constant. Table 1 presents the thickness and the conductivity of PANI layers at $1.0,1.1,1.2$, and $1.3 \mathrm{~V}$. It can be found that the film thickness of PANI increases with the polymerization potential increasing, but the conductivity of PANI decreases. As the potential is $1.0 \mathrm{~V}$, the PANI film is very thin (about $33 \mathrm{~nm}$ ). With the polymerization potential rising, the current density on the PANI/glass electrode is increased, leading to the thickness of PANI film increased also; however, the more thickness of PANI film results in the reduction of conductivity. The best conductivity of PANI deposited on conducting glass substrate reached to $62.59 \mathrm{~S} / \mathrm{cm}$ when the polymerization potential was $1.0 \mathrm{~V}$. Otherwise, the increase of current density on the PANI/glass electrode caused by the rise of potential leads to the peroxidation of PANI, and the conducting emeraldine form is converted into a nonconducting full-oxidation state. This transformation process among the different redox states of PANI also results in the reduction of conductivity.

3.4. Photoelectric Performance of PANI Electrode. The photoelectric properties of DSSCs with PANI/glass and Pt counter electrode are shown in Figure 5, and the results are also listed in Table 2. The result indicates that the PANI/glass electrode deposited at low potential $(1.0 \mathrm{~V})$ with the high conductivity and electrocatalytic activity can obtain the best 


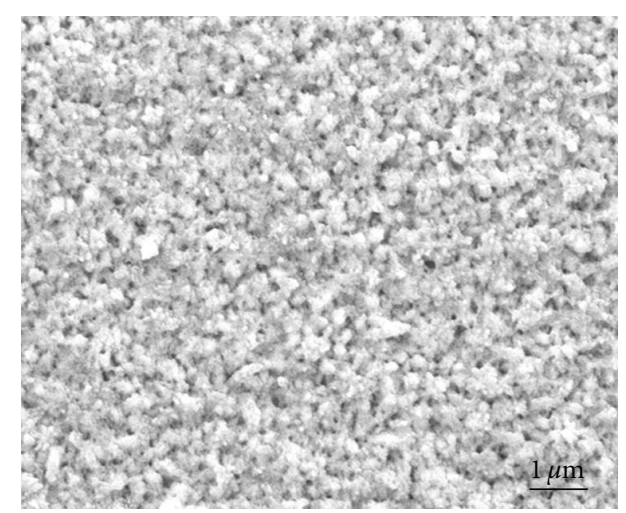

(a)

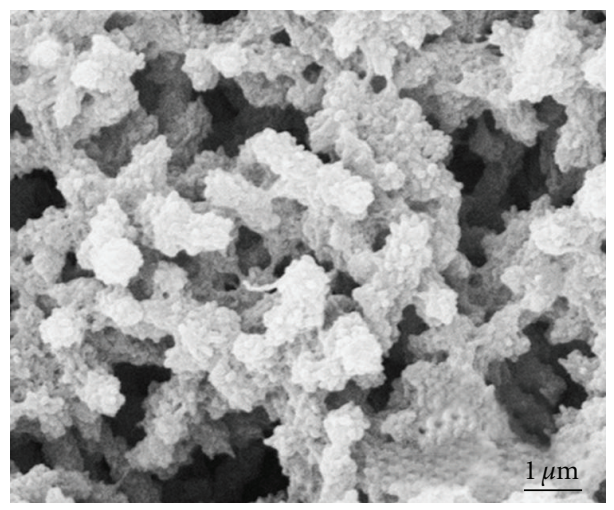

(c)

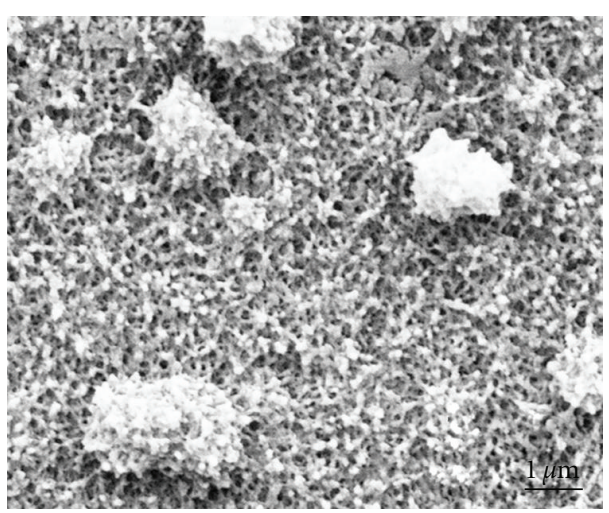

(b)

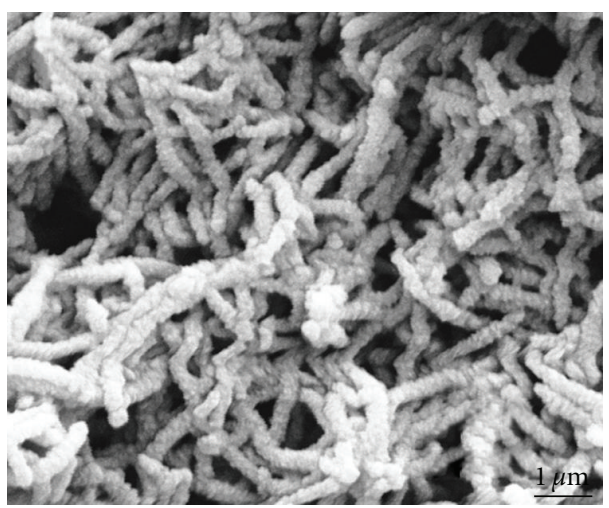

(d)

FIGURE 2: SEM images of polyaniline electrodeposited at (a) $1.0 \mathrm{~V}$, (b) $1.1 \mathrm{~V}$, (c) $1.2 \mathrm{~V}$, (d) $1.3 \mathrm{~V}$.

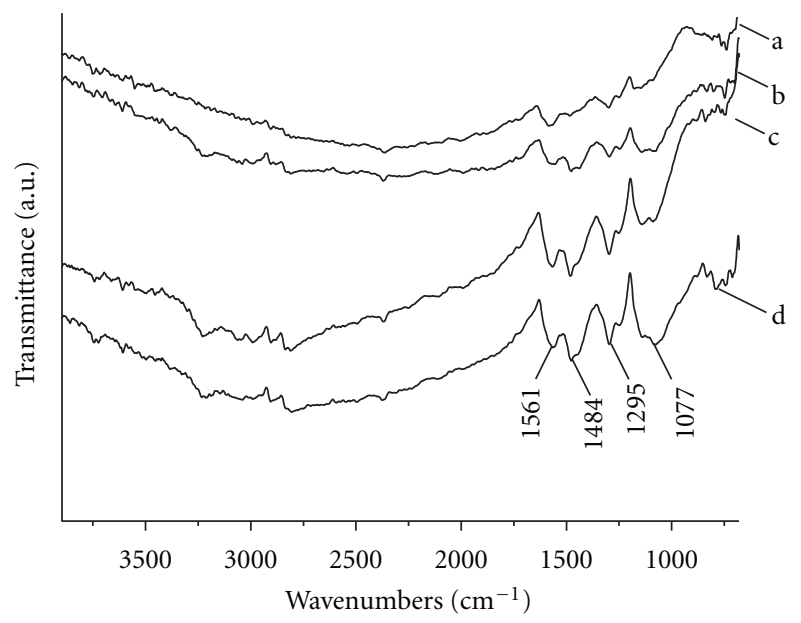

Figure 3: FTIR spectrum of PANI at (a) $1.0 \mathrm{~V}$, (b) $1.1 \mathrm{~V}$, (c) $1.2 \mathrm{~V}$, (d) $1.3 \mathrm{~V}$.

photoelectric conversion efficiency, which reaches to $5.68 \%$. This photoelectric conversion efficiency of DSSC with PANI counter electrode is higher than that with $\mathrm{Pt}$ electrode $(4.51 \%)$, and the fill factor (FF) is about 0.488 , which is higher than Pt electrode (0.483). This improvement of the photoelectric efficiency is referred to the PANI electrode

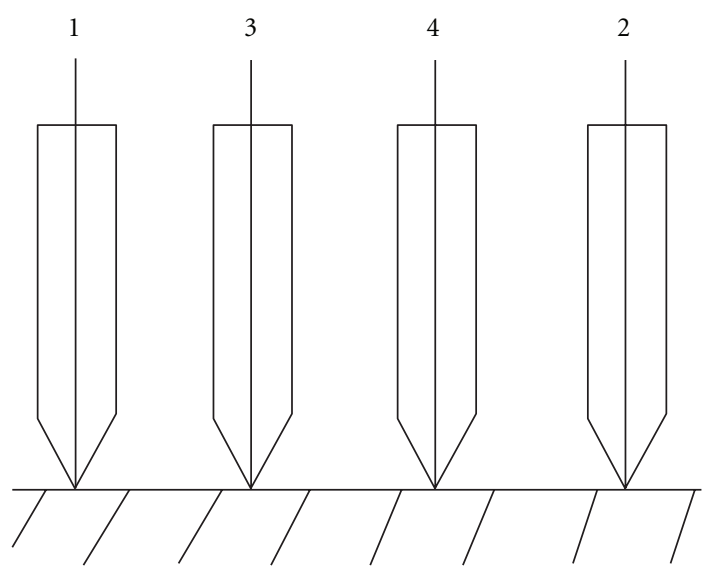

FIgURE 4: The schematic diagram of four-point probes method.

with the higher surface area, the higher electrocatalytic activity, and the lower charge-transfer resistance, compared to $\mathrm{Pt}$ electrode. Moreover, with the potential rising from 1.0 to $1.3 \mathrm{~V}$, the FF has a little change, the Jsc of DSSC with PANI counter electrode has a remarkable decrease, and the energy conversion efficiency of DSSC with PANI electrode descends from $5.68 \%$ to $4.03 \%$. It is due to the reduction of the conductivity and increase of the charge 
TABLE 1: The thickness and conductivity of PANI films under different potential.

\begin{tabular}{lcc}
\hline Sample & $\begin{array}{c}\text { Thickness } d \\
{[\mu \mathrm{m}]}\end{array}$ & $\begin{array}{c}\text { Conductivity } \\
\sigma[\mathrm{S} / \mathrm{cm}]\end{array}$ \\
\hline PANI-1.0 V & 0.033 & 62.59 \\
PANI-1.1 V & 0.212 & 42.97 \\
PANI-1.2 V & 0.651 & 25.18 \\
PANI-1.3 V & 1.367 & 10.41 \\
\hline
\end{tabular}

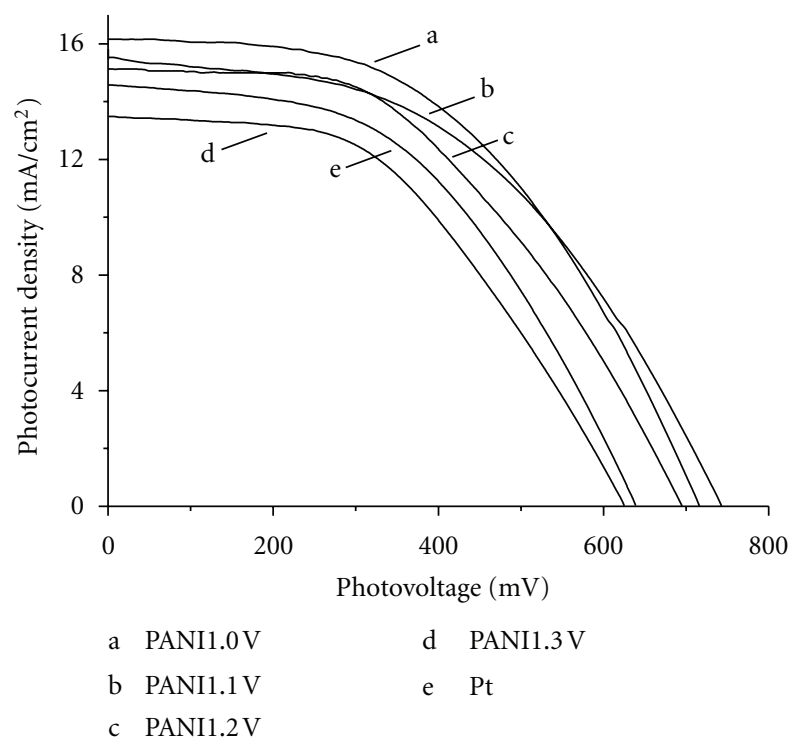

FIGURE 5: Photoelectric properties of DSSCs with different PANI and Pt counter electrodes.

TABle 2: Photovoltaic performance of DSSCs with different PANI and Pt counter electrode.

\begin{tabular}{lcccc}
\hline Electrode & $\begin{array}{c}J_{\mathrm{SC}} \\
{\left[\mathrm{mA} / \mathrm{cm}^{2}\right]}\end{array}$ & $V_{\mathrm{OC}}[\mathrm{mV}]$ & FF & $\begin{array}{c}\text { Efficiency } \\
{[\%]}\end{array}$ \\
\hline PANI-1.0 V & 16.18 & 720 & 0.488 & 5.68 \\
PANI-1.1 V & 15.56 & 740 & 0.476 & 5.48 \\
PANI-1.2 V & 15.19 & 700 & 0.466 & 4.95 \\
PANI-1.3 V & 13.49 & 620 & 0.482 & 4.03 \\
Pt & 14.60 & 640 & 0.483 & 4.51 \\
\hline
\end{tabular}

transmission impedance of PANI electrode with the polymerization potential increasing. As a result, the new PANI counter electrode prepared by electrochemical synthesis method has more predominant photoelectric performance than Pt electrode. Thus, the PANI counter electrode can replace the conventional $\mathrm{Pt}$ counter electrode for reducing the production cost of DSSC.

\section{Summary}

In summary, the PANI counter electrode was successfully fabricated on conducting ITO glass by electrochemical polymerization method. The results showed that the compact layers, nanoparticles, nanorods, and fibrils of PANI successively grew on the surface of glass as the potential rising from $1.0 \mathrm{~V}$ to $1.3 \mathrm{~V}$. The conductivity and photoelectric test indicated that the optimal constant potential of PANI electrodeposition is $1.0 \mathrm{~V}$. The energy conversion efficiency of DSSC with PANI counter electrode at $1.0 \mathrm{~V}$ reached 5.68\%, which was higher than Pt electrode. This improvement corresponds to higher conductivity, higher electrocatalytic activity, and smaller charge-transfer resistance of PANI electrode. Therefore, the PANI counter electrode with the simple preparation procedure, low fabrication cost, and excellent catalytic properties will be a credible alternative of the counter electrode from DSSCs in the future.

\section{References}

[1] P. K. Singh, K. W. Kim, and H. W. Rhee, "Ionic liquid (1Methyl 3-propyl imidazolium iodide) with polymer electrolyte for DSSC application," Polymer Engineering and Science, vol. 49 , no. 5, pp. 862-865, 2009.

[2] B. O’Regan and M. Grätzel, "A low-cost, high-efficiency solar cell based on dye-sensitized colloidal $\mathrm{TiO}_{2}$ films," Nature, vol. 353, no. 6346, pp. 737-740, 1991.

[3] M. Grätzel, "Dye-sensitized cells," Journal of Photochemistry and Photobiology C, vol. 4, pp. 145-153, 2003.

[4] C.-W. Tu, K.-Y. Liu, A.-T. Chien et al., "Enhancement of photocurrent of polymer-gelled dye-sensitized solar cell by incorporation of exfoliated montmorillonite nanoplatelets," Journal of Polymer Science, Part A, vol. 46, no. 1, pp. 47-53, 2008.

[5] Q. Li, J. Wu, Q. Tang et al., "Application of microporous polyaniline counter electrode for dye-sensitized solar cells," Electrochemistry Communications, vol. 10, no. 9, pp. 12991302, 2008.

[6] J. Wu, Q. Li, L. Fan et al., "High-performance polypyrrole nanoparticles counter electrode for dye-sensitized solar cells," Journal of Power Sources, vol. 181, no. 1, pp. 172-176, 2008.

[7] M. Y. Yen, C. Y. Yen, S. H. Liao et al., "A novel carbon-based nanocomposite plate as a counter electrode for dye-sensitized solar cells," Composites Science and Technology, vol. 69, no. 13, pp. 2193-2197, 2009.

[8] Y. Saito, W. Kubo, T. Kitamura, Y. Wada, and S. Yanagida, "I-/I3- redox reaction behavior on poly (3,4ethylenedioxythiophene) counter electrode in dye-sensitized solar cells," Journal of Photochemistry and Photobiology A, vol. 164, no. 1-3, pp. 153-157, 2004.

[9] N. Fukuri, Y. Saito, W. Kubo et al., "Performance improvement of solid-state dye-sensitized solar cells fabricated using poly(3,4-ethylenedioxythiophene) and amphiphilic sensitizing dye," Journal of the Electrochemical Society, vol. 151, no. 10, pp. A1745-A1748, 2004.

[10] J. Han, Y. Liu, and R. Guo, "A novel templateless method to nanofibers of polyaniline derivatives with size control," Journal of Polymer Science Part A, vol. 46, pp. 740-746, 2008.

[11] F. D. R. Amado, L. F. Rodrigues, M. M. C. Forte, and C. A. Ferreira, "Properties evaluation of the membranes synthesized with castor oil polyurethane and polyaniline," Polymer Engineering and Science, vol. 46, no. 10, pp. 14851489, 2006.

[12] I. Sapurina, A. Riede, and J. Stejskal, "In-situ polymerized polyaniline films: 3. Film formation," Synthetic Metals, vol. 123, no. 3, pp. 503-507, 2001. 
[13] A. U. H. A. Shah and R. Holze, "Spectroelectrochemistry of two-layered composites of polyaniline and poly(oaminophenol)," Electrochimica Acta, vol. 53, no. 14, pp. 46424653, 2008.

[14] P. R. Solanki, S. Singh, N. Prabhakar, M. K. Pandey, and B. D. Malhotra, "Application of conducting poly(aniline-copyrrole) film to cholesterol biosensor," Journal of Applied Polymer Science, vol. 105, no. 6, pp. 3211-3219, 2007.

[15] A. Tiwari and S. Gonga, "Electrochemical synthesis of chitosan-co-polyaniline/ $\mathrm{WO}_{3} \cdot n_{3} \mathrm{O}$ composite electrode for amperometric detection of $\mathrm{NO}_{2}$ gas," Electroanalysis, vol. 20, no. 16, pp. 1775-1781, 2008.

[16] P. R. Solanki, N. Prabhakar, M. K. Pandey, and B. D. Malhotra, "Nucleic acid sensor for insecticide detection," Journal of Molecular Recognition, vol. 21, no. 4, pp. 217-223, 2008.

[17] H. Ding, C. Zhu, Z. Zhou, M. Wan, and Y. Wei, "Hydrophobicity of polyaniline microspheres deposited on a glass substrate," Macromolecular Rapid Communications, vol. 27, no. 13, pp. 1029-1034, 2006.

[18] R. Singhal, A. Chaubey, K. Kaneto, W. Takashima, and B. D. Malhotra, "Poly-3-hexyl thiophene langmuir-blodgett films for application to glucose biosensor," Biotechnology and Bioengineering, vol. 85, no. 3, pp. 277-282, 2004.

[19] Q. Qin, J. Tao, Y. Yang, and X. Dong, "In situ oxidative polymerization of polyaniline counter electrode on ITO conductive glass substrate," Polymer Engineering and Science, vol. 51, no. 4, pp. 663-669, 2011.

[20] A. Malinauskas, "Chemical deposition of conducting polymers," Polymer, vol. 42, no. 9, pp. 3957-3972, 2001.

[21] M. Trchová, I. Šeděnková, E. Tobolková, and J. Stejskal, "FTIR spectroscopic and conductivity study of the thermal degradation of polyaniline films," Polymer Degradation and Stability, vol. 86, no. 1, pp. 179-185, 2004.

[22] M. Khalid and F. Mohammad, "Preparation, FTIR spectroscopic characterization and isothermal stability of differently doped fibrous conducting polymers based on polyaniline and nylon-6,6," Synthetic Metals, vol. 159, no. 1-2, pp. 119-122, 2009.

[23] T. Prabhakaran and J. Hemalatha, "Synthesis and characterization of magnetoelectric polymer nanocomposites," Journal of Polymer Science, Part B, vol. 46, no. 22, pp. 2418-2422, 2008.

[24] C. Zhou, J. Han, G. Song, and R. Guo, "Fabrication of poly(aniline-co-pyrrole) hollow nanospheres with triton $\mathrm{X}$ 100 micelles as templates," Journal of Polymer Science, Part A, vol. 46, no. 11, pp. 3563-3572, 2008.

[25] S. Zhou, T. Wu, and J. Kan, "Effect of $\mathrm{Co}^{2+}, \mathrm{Ni}^{2+}, \mathrm{Cu}^{2+}$, or $\mathrm{Zn}^{2+}$ on properties of polyaniline nanoparticles," Journal of Applied Polymer Science, vol. 106, no. 1, pp. 652-658, 2007.

[26] L. Yan and W. Tao, "Synthesis of achiral PEG-PANI rod-coil block copolymers and their helical superstructures," Journal of Polymer Science, Part A, vol. 46, no. 1, pp. 12-20, 2008.

[27] X. Lei and Z. Su, "Conducting polyaniline-coated nano silica by in situ chemical oxidative grafting polymerization," Polymers for Advanced Technologies, vol. 18, no. 6, pp. 472-476, 2007.

[28] M. Kraljić, Z. Mandić, and L. Duić, "Inhibition of steel corrosion by polyaniline coatings," Corrosion Science, vol. 45, no. 1, pp. 181-198, 2003. 

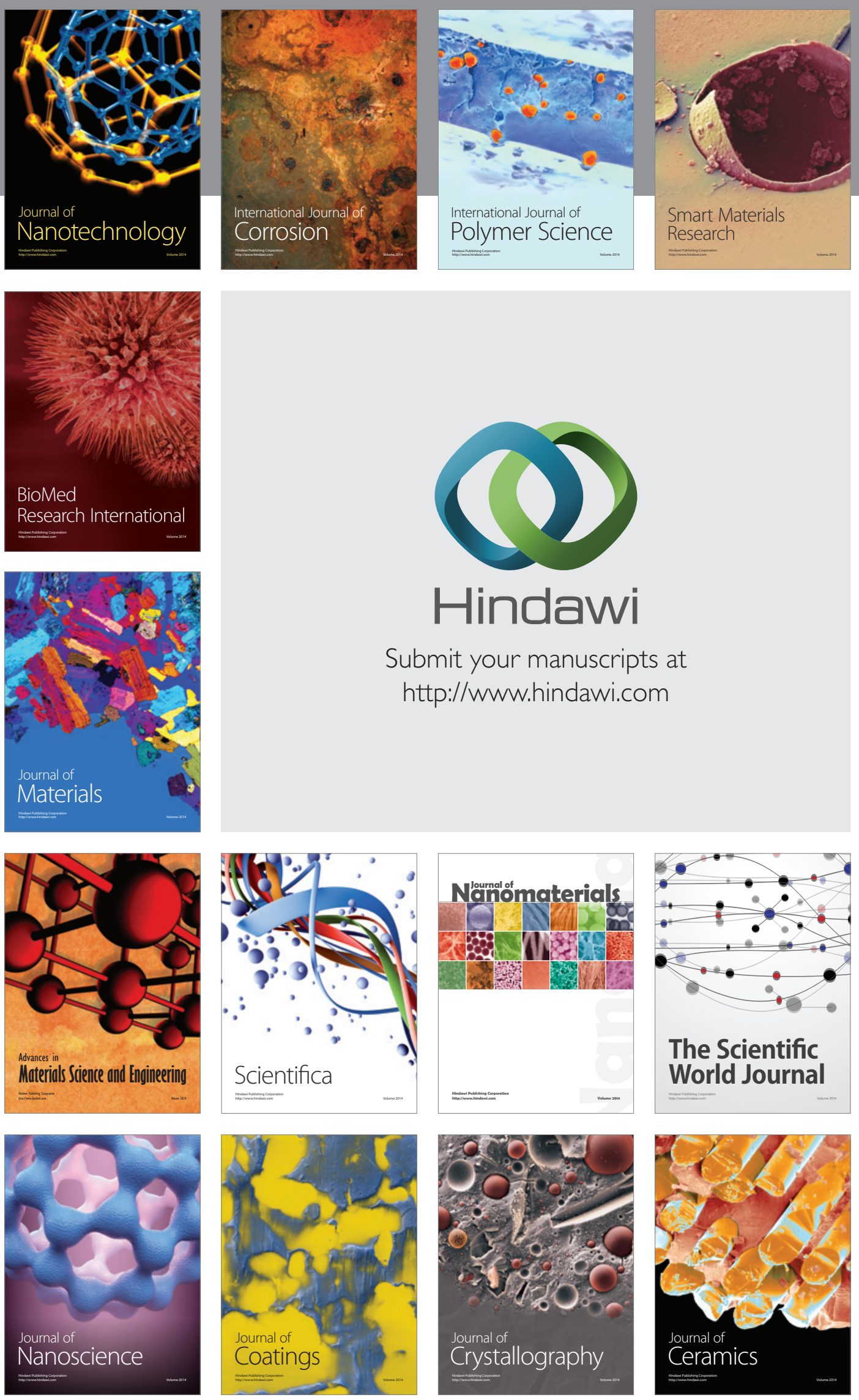

The Scientific World Journal

Submit your manuscripts at

http://www.hindawi.com

\section{World Journal}

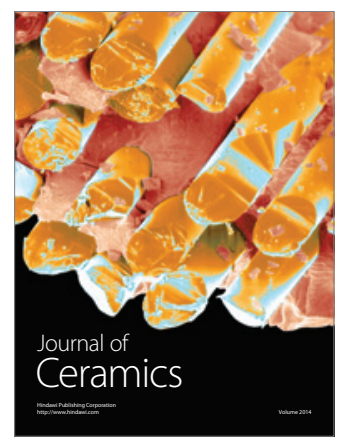

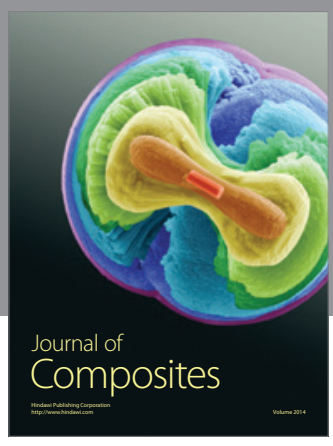
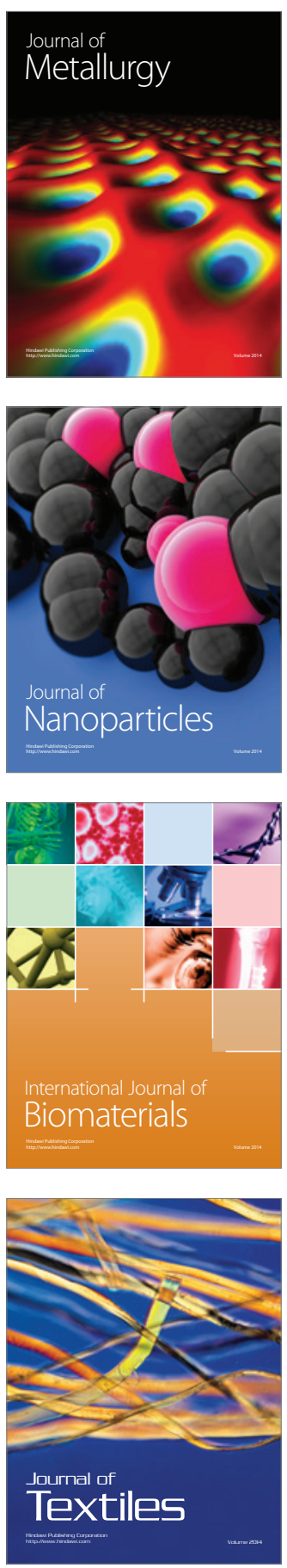